American Journal of

Health, Medicine and Nursing Practice (AJHMN)

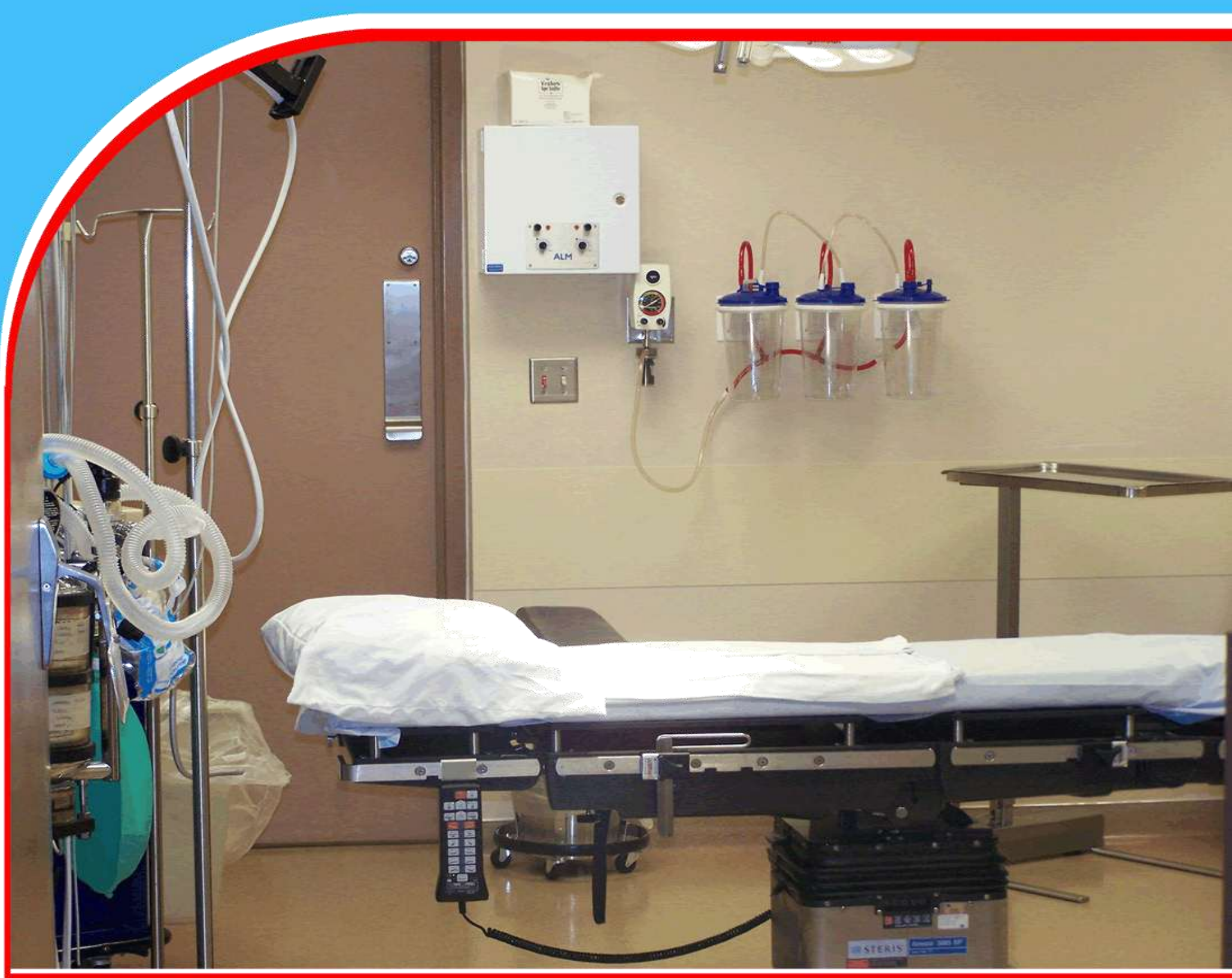

Awareness, Treatment and Control of Hypertension among Traders in Lagos. Achonu Chinmeri U., Amira Christiana O., and Abiola Abdulhakeem O. 


\title{
Awareness, Treatment and Control of Hypertension among Traders in Lagos.
}

\author{
Achonu Chinmeri U. ${ }^{1}$, Amira Christiana O. ${ }^{2}$, Abiola Abdulhakeem 0. ${ }^{3}$ \\ ${ }^{1,3}$ Department of Community Health and Primary Care, College of Medicine, University of \\ Lagos. \\ ${ }^{2}$ Department of Medicine, College of Medicine, University of Lagos. \\ Corresponding Author's Email: achonunmeri@ yahoo.com
}

\begin{abstract}
Introduction: Hypertension is defined as a sustained elevation in the blood pressure of an individual above levels considered normal for the individual's age, sex, race, and body size. Awareness of hypertensive status among traders in Enugu was $29.4 \%$ as of 2017. This study focused on the level of awareness, treatment and control of hypertension among traders in Lagos because of the increasing morbidity and mortality from hypertension in Lagos.

Materials and Methods: This was a descriptive cross-sectional study conducted among a total of 391 traders selected from the Tejuosho market, Iponri market and Orile Iganmu market. Data were collected using an interviewer-administered questionnaire and blood pressure was read using a digital sphygmomanometer as well as anthropometric measurements. Data obtained was analyzed using Epi-info 7.2 software. Analysis was done at a 95\% confidence interval with a P-value of < 0.05 considered statistically significant. Associations between categorical variables were assessed using the chi-square test.

Results: It was found that only $46.6 \%$ of the traders were aware of their hypertensive status with $62.5 \%$ currently on treatment and less than half (43.3\%) being controlled for hypertension.

Conclusions: This study showed that awareness of hypertensive status among the traders was low and the majority of the hypertensive traders were poorly controlled despite treatment greater than 6months.

Recommendations: Traders to be educated about their health regularly, undergo frequent blood pressure screening and for Lagos state ministry of health to stipulate and enforce guidelines for hypertensive patients to get specialist care by regulating the activities of private hospitals in the management of hypertension.
\end{abstract}

Keywords: Hypertension, Awareness, Treatment, Control. 


\section{INTRODUCTION}

High blood pressure, termed "hypertension," is an increasingly important health issue, affects approximately one billion individuals worldwide ${ }^{1,2}$ and is a major risk factor for coronary heart disease, heart failure, cerebrovascular disease and chronic renal failure. ${ }^{3}$ Hypertension is not just in the developed nations but also in the developing countries of the world including those of SubSaharan Africa ${ }^{4}$ consuming an important proportion of their public health budget. ${ }^{5}$

Therefore, the increase in the number of hypertensives cuts across all countries worldwide, in both males and females, usually amongst older adults as the majority of hypertensives are Essential Hypertension making hypertension the single most common non-communicable disease (NCD) causing worldwide morbidity and mortality. ${ }^{6}$ Hypertension which was stated to be a rare problem pre-1990s in black Africans as observed by some researchers, asserting recent increase in individuals with high blood pressure in Africa; to several factors such as urbanisation, changing diets, sedentary lifestyle, and obesity. ${ }^{7}$

Awareness of individuals diagnosed with hypertension has improved over the years with routine screening especially in developed countries. ${ }^{8,9,10,11}$ However there's the persistence of low level of awareness of high blood pressure $(<50 \%)$ especially in the African continent despite rising prevalence $^{12,13,14,15}$ has been established in several studies. The majority of unaware individuals are in developing countries mostly in a rural setting usually tend to be diagnosed when complications of the disease are evident or in the presence of comorbidities like diabetes or dyslipidemia. $^{11,16}$ In Nigeria over $50 \%$ of the hypertensive population were unaware of their condition, and only a few people had an awareness rate of more than 75 per cent. ${ }^{11}$ Several studies done in the country reported a low level of awareness of hypertensive status ranging between $18.9 \%-51.9 \%$ in urban areas $17,18,19,20,21,22$ and $14.2 \%-31.2 \%$ in rural areas. ${ }^{23,24}$

This high level of unawareness of hypertension is attributed to the lack of knowledge about hypertension and its complication amongst most people especially in less developed or rural areas which hinder early detection of the disease. Furthermore, this has deterred known hypertensives to comply with appropriate treatment with supervision as to achieve control. ${ }^{11,25,26}$ Thus levels of control of hypertension is extremely low worldwide especially in sub-Saharan Africa ranging from $3.5-17 \% 11,17,26,27,28,29,30$ even among health care practitioners with adequate knowledge still lacked compliance with antihypertensive medication. ${ }^{31}$ The most important complication of uncontrolled blood pressure is morbidity and mortality of cardiovascular diseases (51\% of stroke and $45 \%$ of deaths due to myocardial infarction. ${ }^{32}$

Traders in sub-Saharan Africa, Nigeria comprise a major sector that contributes to the economic growth of our environment with the majority of them lacking adequate knowledge about their health due to reduced literacy and sedentary lifestyle that pose them at risk of late detection and delay in commencement of treatment for hypertension. Several prevalence studies have been done for hypertension but none has assessed the awareness, treatment and level of control of hypertension among traders. This study assessed the awareness, treatment and level of control of hypertension among traders in Lagos. 


\section{METHODS}

A cross-sectional descriptive study that comprises traders in Tejuosho, Iponri and Orile (Oja) markets selected from 3 levels of market graded by the Lagos state market board. The respondents were traders in these markets. Permission was obtained from the Lagos state market board, Ikeja and respective market leader (Iyaloja/Babaloja) of each market. Some fifteen medical students were recruited and they received a one-day training moderated by the researcher. They assisted the researcher for three hours on the days of data collection. Criteria for inclusion in this study include traders that were $\geq 18$ years, traders trading in the market for at least 6 months, traders that had shops or stalls and traders that consent to participate in the screening exercise. The participants were notified of the reason and nature of the research, verbal consent was obtained from the respondents before data collection. Confidentiality was maintained by not using participants" names. The questionnaires were interviewer-administered to the respondent.

The blood pressure of the subjects was measured after 5-minutes rest with a Digital sphygmomanometer using an appropriate cuff size in the left arm, leg uncrossed and participants in a sitting position. Korotkoff's 1st and 5th sounds were used as the systolic and diastolic blood pressure and two mean readings were used for each participant taken five minutes apart Hypertension was defined according to British Hypertension Society (BHS). Information on biodata, marital status of the traders, level of educational qualification if any, an estimate of income per month, their respective roles in the shop or stalls i.e. if they were the owners or sales representative or apprentice in the shop, an estimate of the number of hours they work per day, duration in years they have been trading (at most 6 months).

Awareness for hypertension was assessed among individuals with hypertension and was defined as a trader's report of a prior diagnosis of hypertension made by a health professional. Treatment of hypertension was defined as self-reported use of antihypertensive medication prescribed by a medical doctor. ${ }^{31}$ Hypertension control was defined as the proportion of hypertensive individuals with SBP less than $140 \mathrm{mmHg}$ and DBP less than $90 \mathrm{mmHg} .{ }^{31}$

\section{STATISTICAL DATA}

Statistical analysis Data were entered in Microsoft @ Excel and analyzed using Epi info ® 2007. The analysed data were presented as frequency tables and charts, means and standard deviation. Mean values of continuous variables were compared using the student t-test. Percentages were compared using the $\chi^{2}$ test. Analysis was done by comparing mean values obtained for male and female subjects and subjects with and without hypertension. Statistical significance was assumed at a $\mathrm{P}$-value $<0.05$. 
American Journal of Health, Medicine and Nursing Practice

ISSN 2520-4017 (Online)

Vol.7, Issue 2, pp $1-14,2022$

www.ajpojournals.org

\section{RESULTS}

Table 1: Socio-demographic, socio-economic and work status of respondents.

\begin{tabular}{|c|c|c|}
\hline Variables & Frequency $(n=391)$ & Percentage (\%) \\
\hline \multicolumn{3}{|l|}{ Age in years } \\
\hline $18-24$ & 74 & 18.9 \\
\hline $25-34$ & 70 & 17.9 \\
\hline $35-44$ & 94 & 24.0 \\
\hline $45-54$ & 80 & 20.5 \\
\hline $55-64$ & 47 & 12.0 \\
\hline$\geq 65$ & 26 & 6.7 \\
\hline \multicolumn{3}{|l|}{$\overline{\mathbf{S e x}}$} \\
\hline Male & 91 & 23.3 \\
\hline Female & 300 & 76.7 \\
\hline \multicolumn{3}{|l|}{ Marital status } \\
\hline Single & 106 & 27.1 \\
\hline Married & 251 & 64.1 \\
\hline Widowed & 23 & 5.9 \\
\hline Divorced & 9 & 2.3 \\
\hline Separated & 1 & 0.3 \\
\hline Engaged & 1 & 0.3 \\
\hline \multicolumn{3}{|l|}{ Religion } \\
\hline Christianity & 212 & 54.2 \\
\hline Islam & 179 & 45.8 \\
\hline \multicolumn{3}{|l|}{ Level of education } \\
\hline No formal education & 31 & 7.9 \\
\hline Primary & 40 & 10.2 \\
\hline Secondary & 216 & 55.3 \\
\hline Tertiary & 104 & 26.6 \\
\hline \multicolumn{3}{|l|}{ Role in shop } \\
\hline Owner & 256 & 65.5 \\
\hline Sales assistant & 119 & 30.4 \\
\hline Manager & 6 & 1.5 \\
\hline Apprentice & 8 & 2.1 \\
\hline Supplier/ distributor & 2 & 0.5 \\
\hline \multicolumn{3}{|c|}{ Hours at work in a day } \\
\hline$<4$ hours & 11 & 2.8 \\
\hline $4-8$ hours & 113 & 28.9 \\
\hline $9-12$ hours & 221 & 56.5 \\
\hline$>12$ hours & 46 & 11.8 \\
\hline
\end{tabular}


American Journal of Health, Medicine and Nursing Practice ISSN 2520-4017 (Online)

Vol.7, Issue 2, pp $1-14,2022$

www.ajpojournals.org

\begin{tabular}{lrr}
\hline Duration of trading job & & \\
$<5$ years & 152 & 38.9 \\
$6-10$ years & 68 & 17.4 \\
$11-15$ years & 44 & 11.3 \\
$16-20$ years & 28 & 7.2 \\
$21-25$ years & 28 & 7.2 \\
$26-30$ years & 21 & 5.4 \\
$>30$ years & 50 & 12.8 \\
\hline
\end{tabular}

A total of three hundred and ninety-one traders were screened. There were $91(23.3 \%)$ males and the mean age was $40.5 \pm 14.9$; the age range was $18-82$ years. Figure 1 shows the age distribution of the population studied; $153(39.1 \%)$ were below 45 years. In terms of educational qualification, $59(7.9 \%)$ respondents had no formal education, $40(10.2 \%)$ had primary school education, 216 $(59.3 \%)$ achieved secondary school education and $104(26.6 \%)$ achieved tertiary education. The majority of the respondents $256(65.5 \%)$ were shop owners, $119(30.4 \%)$ were sales assistants, $6(1.5 \%)$ were managers, $8(2.1 \%)$ were apprentices and $2(0.5 \%)$ of the respondents were distributors/suppliers. In terms of years of trading, 152(38.9\%) of the respondents have been trading < 5years while 50(12.8\%) have been in the profession for over 30years.

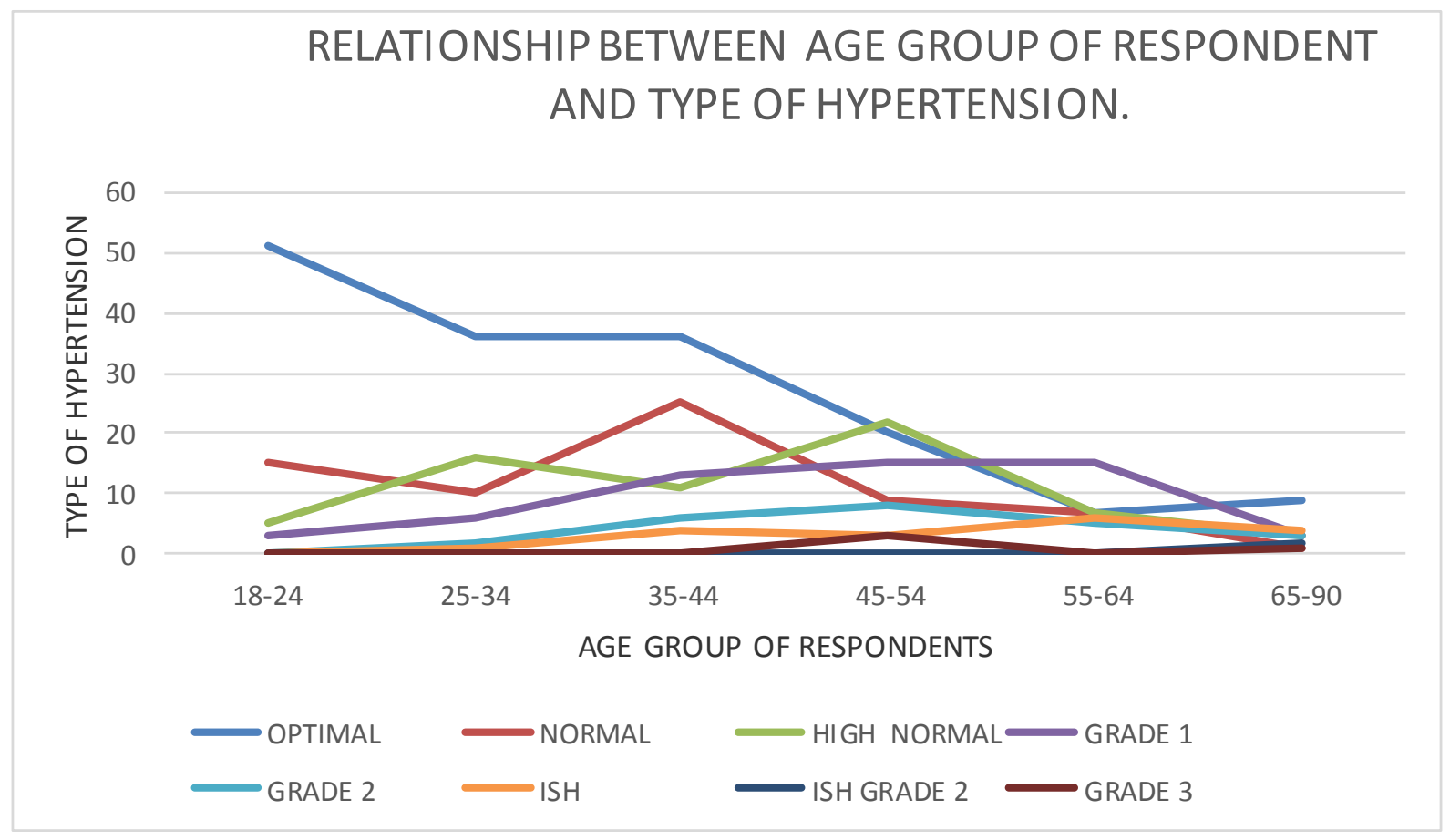

Figure 1: relationship between age group of respondents and type of hypertension

Respondent in the age group 18-24 has more normotensive individuals while age groups 45-54, $55-64$ have a higher percentage of respondents respectively in grade $1(29.2 \%, 27.1 \%)$, grade 2 $(28.6 \%, 28.6 \%)$ and grade $3(66.7 \%)$ hypertension. Respondents in age groups $55-64,65-90$ have a higher percentage of Isolated Systolic Hypertension $(30.0 \%, 30.0 \%)$ respectively. 
American Journal of Health, Medicine and Nursing Practice ISSN 2520-4017 (Online)

Vol.7, Issue 2, pp $1-14,2022$

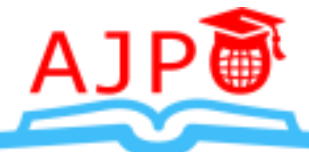

www.ajpojournals.org

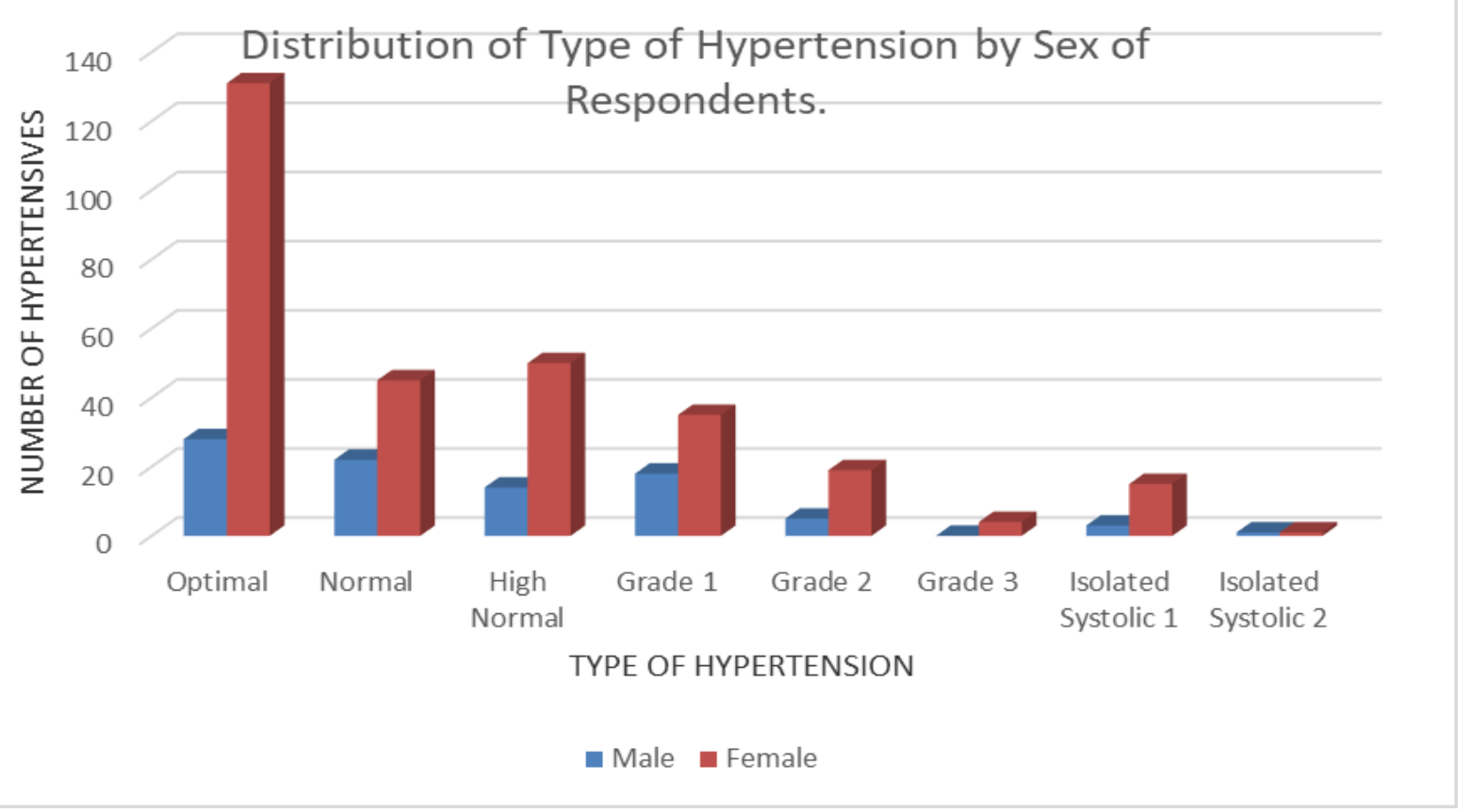

Figure 2: Distribution of type of hypertension by sex of respondents.

The above figure shows that the majority (35\%) of the hypertensive respondents were females and in grade 1 type of hypertension. There was an equal number of male (1\%) and female (1\%) respondents with isolated systolic 2 .

AWARENESS, TREATMENT AND CONTROL OF HYPERTENSION STATUS

Table 2: Awareness of hypertension status

\begin{tabular}{lcc}
\hline Awareness of hypertension & Frequency $(\mathbf{N = 1 2 1})$ & Percentage (\%) \\
\hline Aware & 48 & 39.6 \\
Unaware & 73 & 60.3 \\
\hline \multicolumn{3}{c}{ Known hypertensive Traders on Treatment } \\
\hline Treatment & Frequency & Percentage \\
& & $(\%)$ \\
Controlled & 13 & 10.7 \\
Not controlled & 17 & 14.1 \\
\hline Total & 30 & 24.8 \\
\hline No treatment & & \\
controlled & 5 & 4.1 \\
Not controlled & 13 & 10.7 \\
\hline Total & 18 & 14.8 \\
\hline
\end{tabular}

About $48(39.6 \%)$ of 121 respondents were aware of their hypertensive status before the study, $60.3 \%$ of those unaware stated the wrong diagnosis of their hypertensive status and $23(31.5 \%)$ of those unaware $(73,60.3 \%)$ stated they were not sure nor could remember if they had been 
American Journal of Health, Medicine and Nursing Practice

ISSN 2520-4017 (Online)

Vol.7, Issue 2, pp $1-14,2022$

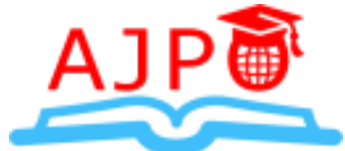

www.ajpojournals.org

previously diagnosed. Thirty $(24.8 \%)$ of known hypertensive traders were on treatment. However, only $13(10.7 \%)$ traders of those on treatment had their blood pressure $<140 / 90 \mathrm{mmHg}$.

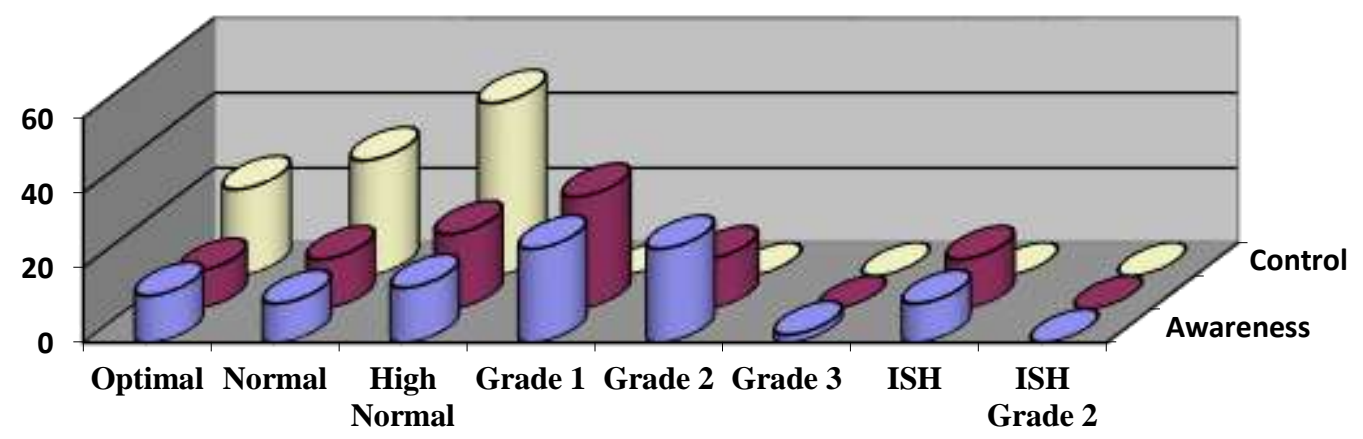

Figure 3: Awareness of diagnosis, treatment and control of hypertension.

Awareness of hypertension was high in grade 1 and 2 types of hypertensives with the majority of grade 1 hypertensive traders on treatment but grade 3 and isolated systolic hypertensive traders mostly unaware of their hypertensive status with all of the traders with grade 3 hypertension on no form of treatment. More females $(91,75.2 \%)$ were hypertensive compared with the males (30, $24.8 \%$ ) but the majority of the females $(41,33.9 \%)$ were aware of their hypertensive status before the study. The level of treatment and control was quite high in females $(23.1 \%, 9.9 \%)$ than males $(1.7 \%, 0.8 \%)$.

\section{DISCUSSION}

Awareness of hypertension refers to having been informed of one's hypertensive status by a health professional. Generally, the level of awareness within the hypertensive population varies considerably in regions; both within ${ }^{33}$ and between countries of the world ${ }^{34,35}$ with higher levels in developed countries ${ }^{8} 70 \%$ and $58 \%$ in the United States and Canada ${ }^{9}$ respectively and reduces

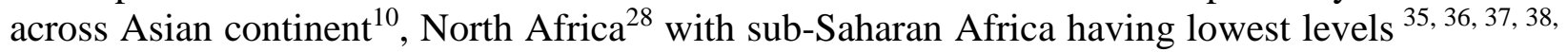
$39,40,41$. This is due to the availability of health insurance coverage, adequate and conducive health facilities and high literacy levels in developed countries even North Africa compared to pathetic health care in most sub-Saharan and East Africa. ${ }^{11}$ Moreover female sex, older age and urban residence were said to be factors associated with awareness and control of hypertensive status ${ }^{39}$ worldwide.

In this study awareness of hypertension was less than average as only $39.6 \%$ of respondents were aware of their hypertensive status, this is in contrast to studies done among adult residents in $\operatorname{Lagos}^{17}$ with $18.9 \%$ of respondents level of awareness of hypertensive status, $10.6 \%$ among apparently healthy adults in Umuahia ${ }^{42}, 7.4 \%$ in urban poor communities Ghana ${ }^{26}$ this agrees with a review of studies done by Kayima et $\mathrm{al}^{11}$ in which West Africa (Nigeria inclusive) is said to have the lowest levels of hypertension in Africa. This may be due to the poor impact of health messages and teaching in the prevention of NCDs like hypertension which hasn't been reduced in recent 
times. The high rate of unawareness could be due to the relative absence of symptoms in hypertension until the late stages when complications set in and the individuals present at the health facility for these symptoms, hypertension may then be diagnosed incidentally. The level of awareness was high $64.7 \%$ in a study done among the health workforce in Nigeria. ${ }^{43}$ This is because, the study was done among health workers; who have a higher knowledge based on educational qualification, lots of medical exposure coupled with years of experience in the management of patients than the general populace with the majority having little or no knowledge about prevention of NCDs that can be caused by hypertension. ${ }^{44}$

Thirty $(24.8 \%)$ of respondents who were aware of their hypertensive status were currently on treatment for hypertension at the time of this study with antihypertensive. Blood pressure was controlled in only $13(10.7 \%)$ of them that were on treatment. The level of control also is poor as only $10.7 \%$ of them that were on treatment had their blood pressure $<140 / 90 \mathrm{mmHg}$, as about $56.7 \%$ of those who were on treatment but still hypertensive. This is similar to the study in Ghana ${ }^{45}$ whereby the level of awareness for hypertension was low with treatment and control far lower like in our study. ${ }^{25,46}$ This may be attributed to poor compliance with the antihypertensive drug by respondents on treatment as most antihypertensives are to be taken once daily. Also, the poor choice of right antihypertensive by health provider $^{31}$ which should always be a medical practitioner especially if the rate of compliance of a patient with antihypertensive is high but in our environment due to poor health-seeking behaviour among individuals in most parts of Lagos coupled with financial constraints restricts most hypertensives to seek for consultation from experts about their health issues rather patronize the services of a nearby chemist or any other health provider ${ }^{31}$ who is not a medical practitioner. Issues governing the referral of patients with highly elevated systolic and diastolic blood pressure of individuals as seen in this study as most of the known hypertensives that were not controlled were still managed by their respective general practitioners especially in the private sector. ${ }^{31}$

The level of awareness was observed to increase with age until age group $>65$ years, a decline in the level of awareness from $4.6 \%$ in the age group 54-64 years to $0.8 \%$ in age group > 65 years and this is in disagreement with reports from other studies, ${ }^{47}$ however age was statistically significant with awareness of hypertensive status in this study. Awareness was highly significant with gender $\mathrm{p}=0.003$ as the majority of those aware are females $(85.4 \%)$ than male traders $(14$. $6 \%$ ). This is similar to the study done in Umuahia. ${ }^{11,18}$ This differs from our study in the review of studies ${ }^{40}$ of various countries of the world. This is because the sample size and procedures in our study are quite different from theirs as well as different regions. This may also be related to the differences in their health-seeking behaviour since females are more likely than males to present at the hospital for ill-health and all because of their more frequent contacts with the health facility (antenatal care, family planning clinic) hence a greater opportunity for a causal blood pressure check. The variation in the level of awareness of our study and that among traders in Enugu, ${ }^{20}$ even though awareness of hypertensive status was below average in both studies, it was low in their study (29.4\%), also male traders were more aware than female traders. This may be due to a slight increase in no of male traders recruited in their study.

Owners of shops were more aware of their hypertensive status $(95.8 \%)$ than other respondents in other classes of positions in the shop. However marital status was not significant with awareness 
of hypertensive status but the majority of traders $(77.1 \%)$ aware of their status were married than traders not married. This has grave implications due to the asymptomatic nature of hypertension, whose complications can be manifest by the time of accessing care because of late detection and treatment of elevated blood pressure over the years. Ignorance of the presence of the disease is a risk factor for the development of complications. It has been referred to as a "silent killer" because in the absence of detectable symptoms it leads to continuous and progressive damage to vital (target) organs in the body.

There was no significant relationship between awareness of hypertension and educational qualification with $\mathrm{p}=0.008$, this is similar to Okwuonu et al. ${ }^{18}$ However, awareness of hypertensive status was higher among respondents with secondary education this is because the majority of traders in Lagos are with secondary education with only few traders that progressed to tertiary level of education. The low level of awareness of hypertensive status has worsened the prevention of complications of the disease in which Cerebrovascular accident has been the most common cause of emergency presentation in Nigeria. ${ }^{16}$ Most of these patients are elderly with little or no knowledge about hypertension and its sequelae. Furthermore, it's been proven in recent studies that awareness of hypertensive status do not correspond to treatment nor control of hypertension. ${ }^{11}$, 20, 22, 29, 31 This is because the majority of known hypertensive are not compliant with treatment nor being reviewed periodically by a specialist and thus makes the control of hypertension extremely difficult.

\section{CONCLUSION}

Awareness of hypertensive status was poor in this study as more than half of the traders were unaware of their hypertensive status, although the level of awareness was higher among the female traders than male traders. Treatment and control for those aware of their hypertensive status were low $(24.7 \%, 10.7 \%)$. Based on the study findings the following was recommended:

\section{a) HEALTH EDUCATION}

Educating traders in which majority of them are with some level of education starting from their market leaders in their respective subgroups about the causes, effects and complications of Noncommunicable diseases like hypertension as it's majorly asymptomatic, unlike most communicable diseases.

\section{b) COMPULSORY SCREENING}

Compulsory screening of traders at least quarterly should be enforced and strictly complied with. This can be effective by:

i) Adequate planning by establishing a medical or health board by each facility manager in the market to oversee concerning preventive health practices mainly in the market.

ii) For increased participation of all the traders in each market, should decide on the day, a month for the screening to be done.

iii) Health market boards should engage NGOs, Health institutions recommended like public and private hospitals, pharmaceutical companies, Dieticians, medical laboratories and radiological 
American Journal of Health, Medicine and Nursing Practice ISSN 2520-4017 (Online)

Vol.7, Issue 2, pp $1-14,2022$

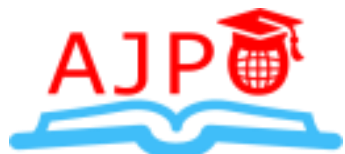

www.ajpojournals.org

centres to be in attendance on their screening days to help to increase the level of awareness and practice of mainly early preventive and also the curative aspect of NCDs like hypertension.

iv) The state government should make a market health safety policy to be executed by the market leaders and facility managers through the local government to ensure any new trader who acquires or rents a shop in every market must be screened or provide a medical report of their recent body checkup and vital findings, especially blood pressure. This is not to hinder traders hypertensive from engaging in business activities but to increase their level of awareness as awareness of hypertension among traders, as deducted from this study is very poor.

c) Government should monitor the activities of private hospitals, in general, practise, that are not specialists by routinely checking its hospital files. This is because some of the known hypertensive traders in this study make use of private hospitals and are on two or more antihypertensives, even with $>50 \%$ compliance, blood pressure is still poorly controlled. There should be a need for referral to an appropriate specialist or consultant e.g. Nephrologist, Cardiologist to help in the management of these patients as to increase the level of control among hypertensive traders in Lagos.

\section{REFERENCES.}

1. Kearney PM, Whelton M, Reynolds K, Muntner P, Whelton PK, He J. Global burden of hypertension: analysis of worldwide data. Lancet [Internet]. 2005 Jan [cited 2017 Nov 12];365(9455):217-23. Available from: http://www.ncbi.nlm.nih.gov/pubmed/15652604.

2. Mensah GA, Bakris G (2011). The United Nations high-level meeting addresses Noncommunicable diseases, But Where Is Hypertension? J. Clin. Hypertens. 13(11):787-790.

3. World Health Organization. Global status report on non-communicable diseases 2010. World Health [Internet]. 2010;176. Available from:

http://whqlibdoc.who.int/publications/2011/9789240686458_eng.pdf

4. Belue R, Okoror TA, Iwelunmor J, Taylor KD, Degboe AN, Agyemang C, et al. Globalization and Health: An overview of cardiovascular risk factor burden in sub-Saharan African countries: a socio-cultural perspective. $2009 ; 12: 1-12$.

5. Houtman I, Jettinghoff K, Cedillo L. Raising awareness of stress at work in developing countries. Prot Work Heal Ser [Internet]. 2007;(6):1-51. Available from:

http://scholar.google.com/scholar?hl=en\&btnG=Search\&q=intitle:Raising+Awareness+of+Stress +at+Work+in+Developing+Countries\#1.

6. Rodgers A, Ezzati M, Vander Hoorn S, Lopez AD, Lin RB, Murray CJ. Distribution of major health risks: findings from the Global Burden of Disease study. PLoS Med 2004; $1: \mathrm{e} 27$.

7. Ogah OS, Okpechi I, Chukwuonye II, Akinyemi JO, Onwubere BJ, Falase AO, et al. Blood pressure, the prevalence of hypertension and hypertension-related complications in Nigerian Africans: A review. World J Cardiol [Internet]. 2012 Dec 26 [cited 2017 Nov 12];4(12):327-40. Available from: http://www.ncbi.nlm.nih.gov/pubmed/23272273. 
American Journal of Health, Medicine and Nursing Practice

ISSN 2520-4017 (Online)

Vol.7, Issue 2, pp $1-14,2022$

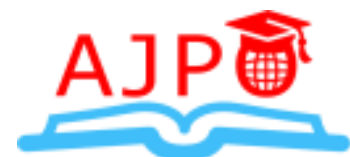

www.ajpojournals.org

8. Wolf-Maier K, Cooper RS, Banegas JR, Giampaoli S, Hense H-W, Joffres M, et al. Hypertension Prevalence and Blood Pressure Levels in 6 European Countries, Canada, and the United States. JAMA [Internet]. American Medical Association; 2003 May 14 [cited 2017 Nov 13];289(18):2363. Available from:

http://jama.jamanetwork.com/article.aspx?doi=10.1001/jama.289.18.2363.

9. Ong, K. L., and Cheung, B. (2007), "Prevalence, awareness, treatment, and control of hypertension among United States adults 1999-2004", Hypertension, 49, pp 69-75.

10. Zhang, X, Zhu, M, Dib, H. H, Hu, Z,Tang,S, Zhang, T. and Ming, X. (2009), “Knowledge, Awareness, Behaviour (KAB) and control of hypertension among urban elderly in Western China", International Journal of Cardiology, 137(1), pp 9-15.

11. Kayima J, Wanyenze RK, Katamba A, Leontsini E, Nuwaha F. Hypertension awareness, treatment and control in Africa: a systematic review. BMC Cardiovasc Discord [Internet]. 2013;13(1):54. Available from: http://bmccardiovascdisord.biomedcentral.com/articles/10.1186/1471-2261-13-54.

12. Tesfaye, B. (2009), "Population-based prevalence of high blood pressure among adults in Addis Ababa: uncovering a silent epidemic", BMC Cardiovascular Disorders, 9(39), pp 1-9.

13. Muhihi, A., Njelekela, M., Mpemberi, R.Masesa, Z, Kitamori, K, Mori, M, Kato, N, Mtabaji, $\mathrm{J}$ and Yamori, Y(2012), "Physical activity and cardiovascular risk factors among young and middle-aged in urban Mwanza, Tanzania", Pan African Medical Journal, Vol. 11 No.11, doi:10.11604/pamj.2012.11.11.557.

14. Azubuike, S. O., and Kurmi, R. (2014), “Awareness, practices, and prevalence of hypertension among rural Nigerian women". Archives of Medicine and Health Sciences, 2(1), pp 23-28.

15. Abdullahi, A. A. and Amzat, J. (2011), "Knowledge of hypertension among the staff of University of Ibadan", Nigeria Journal of Public Health and Epidemiology, 3(5), pp204-209.

16. Olusegun-Joseph AD, Akande O, Otrofanowei E, Nwoye EO, Olopade OB, Ajuluchukwu JN. Medical mortality in an emergency department in Nigeria: the transition is obvious! Afr Health Sci. 2021 Mar;21(1):172-179. DOI: 10.4314/ahs.v21i1.23. PMID: 34394295; PMCID: PMC8356607.

17. Daniel O, Adejumo O, Adejumo E, Owolabi R, Braimoh R, Salako A. Prevalence, Awareness and Factors Associated with Hypertension among Adult Residents in Lagos: A Population-Based Study. Br J Med Med Res [Internet]. 2015;8(10):874-82. Available from: http://www.sciencedomain.org/abstract.php?iid=1122\&id=12\&aid=9505.

18. Okwuonu C, Ojimadu N, Chimezie O, Madudonu U, Ogbulafor N, Ogah O. Awareness of blood pressure status, undiagnosed hypertension and proteinuria among adults in Umuahia, South-East Nigeria. Sahel Med J [Internet]. 2016;19(2):82. Available from: http://www.smjonline.org/text.asp?2016/19/2/82/186035. 
American Journal of Health, Medicine and Nursing Practice ISSN 2520-4017 (Online)

Vol.7, Issue 2, pp $1-14,2022$

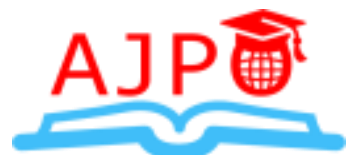

$\underline{\text { www.ajpojournals.org }}$

19. Yetunde Abosede Zaid, (2017) "High Blood Pressure Awareness among Residents in Lagos State, Nigeria: The Role of Librarians in the Dissemination of Health Information", Library Review, Vol. 66 Issue: 4/5, DOI: 10.1108/LR-06-2016-0056. http://dx.doi.org/10.1108/LR-062016-0056.

20. Ulasi, I. I, Ijoma, C. K, Onwubere, B. J, Arodiwe, E, Onodugo, O and Okafo, C (2011), "High prevalence and low awareness of hypertension in a market population in Enugu, Nigeria", International Journal of Hypertension, pp 11, 1-5.

21. Odugbemi TO, Onajole AT, Osibogun AO. Prevalence of cardiovascular risk factors amongst traders in an urban market in Lagos, Nigeria. Niger Postgrad Med J [Internet]. 2012;19(1):1-6. Available from: http://www.ncbi.nlm.nih.gov/pubmed/22430594.

22. Amira CO, Akinkugbe O, Fasanmade O, Ozoh O, Bandele E. Prevalence and awareness of hypertension in a rural community in South-West Nigeria. Nig Qt J Hosp Med. 2014;24(2):96101.

23. Oladapo, O. O., Salako, L, Sodiq, O., Shoyinka, K., Adedapo, K., and Falase, A. O. (2010), "A prevalence of cardiometabolic risk factors among a rural Yoruba south-western Nigerian population: a population-based survey”, Cardiovascular Journal of Africa, 21, pp 26-31.

24. Omuemu, O. H., Okojie, and C. E. Omuemu, (2007), "Awareness of high blood pressure status, treatment and control in a rural community in Edo State", Nigerian Journal of clinical practice, 10(3), pp 208-212.

25. Wu Y, Huxley R, Li L, Anna V, Xie G, Yao C, Woodward M, Li X, Chalmers J, Gao R, Kong L, Yang X; China NNHS Steering Committee; China NNHS Working Group. Prevalence, awareness, treatment, and control of hypertension in China: data from the China National Nutrition and Health Survey 2002. Circulation. 2008 Dec 16;118(25):2679-86. DOI: 10.1161/CIRCULATIONAHA.108.788166. PMID: 19106390.

26. Awuah RB, Anarfi JK, Agyemang C, Ogedegbe G, Aikins A de-G. Prevalence, awareness, treatment and control of hypertension in urban poor communities in Accra, Ghana. J Hypertens [Internet]. 2014;32(6):1203-10. Available from: http://content.wkhealth.com/linkback/openurl?sid=WKPTLP:landingpage $\& a n=00004872$ 201406000-00010.

27. Thorogood M, Connor M, Tollman S, Lewando Hundt G, Fowkes G, Marsh J. A crosssectional study of vascular risk factors in a rural South African population: data from the Southern African Stroke Prevention Initiative (SASPI). BMC Public Health 2007;7:326.

28. Hypertension Study Group. Prevalence, awareness, treatment and control of hypertension among the elderly in Bangladesh and India: a multicentre study. Bull World Health Organ 2001;79:490-500.

29. Mohamed hussein MS, Nagri ZI, Manji KP. Prevalence, Risk Factors, Awareness, and Treatment and Control of Hypertension in Mafia Island, Tanzania. 2016;2016.

30. Kalani Z, Abdi H, Shahbazi L, Salimi T, Amini PM. Hypertension in the Yazd adult population. Payesh. 2011;10(1):101-7. 
American Journal of Health, Medicine and Nursing Practice ISSN 2520-4017 (Online)

Vol.7, Issue 2, pp $1-14,2022$

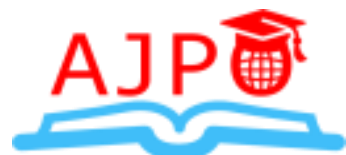

$\underline{\text { www.ajpojournals.org }}$

31. Bosu WK. The prevalence, awareness, and control of hypertension among workers in West Africa: A systematic review. Glob Health Action. 2015;8(1).

32. Tesfaye B, Haile D, Lake B, Belachew T, Tesfaye T, Abera H. Uncontrolled hypertension and associated factors among adult hypertensive patients on follow-up at Jimma University teaching and specialized hospital: a cross-sectional study. Res Rep Clin Cardiol 2017;8:21-29. http://doi.org/https://doi.org/10.2147/RRCC.S132126.

33. Gómez-Olivé FX, Ali SA, Made F, Kyobutungi C, Nonterah E, Micklesfield L, et al. Stark Regional and Sex Differences in the Prevalence and Awareness of Hypertension: An H3Africa AWI-Gen Study Across 6 Sites in Sub-Saharan Africa. Global Heart. 2017;12(2):81-90.

34. Ifunanya G. Uzoma, Geraldine ifunanya pg/mph/ 05/45106. 2010;(August).

35. Pereira M, Lunet N, Azevedo A, Barros H: Differences in prevalence, awareness, treatment and control of hypertension between developing and developed countries. Journal of hypertension 2009, 27(5):963-975.

36. Ataklte F, Erqou S, Kaptoge S, Taye B, Echouffo-Tcheugui JB, Kengne AP. The burden of undiagnosed hypertension in sub-Saharan Africa. A systematic review and meta-analysis. Hypertension. 2014;65:291-8.

37. Van de Vijver SJ, Oti SO, Agyemang C, Gomez GB, Kyobutungi C. Prevalence, awareness, treatment and control of hypertension among slum dwellers in Nairobi, Kenya. J Hypertens 2013;31(5):1018-1024.

38. Guwatudde D, Mutungi G, Wesonga R, Kajjura R, Kasule H, Muwonge J, et al. The epidemiology of hypertension in Uganda: findings from the national non-communicable diseases risk factor survey. PLoS One. 2015;10(9):e0138991.

39. Mosha NR, Mahande M, Juma A, Mboya I, Peck R, Urassa M, et al. Prevalence, awareness and factors associated with hypertension in North West Tanzania. Glob Health Action. 2017;10(1):1321279.

40. Lloyd-Sherlock P, Beard J, Minicuci N, Ebrahim S, Chatterji S. Hypertension among older adults in low- and middle-income countries: prevalence, awareness and control. Int J Epidemiol [Internet]. 2014 Feb 1 [cited 2017 Nov 14];43(1):116-28. Available from: http://www.ncbi.nlm.nih.gov/pubmed/24505082.

41. Damasceno A, Azevedo A, Silva-Matos C, Prista A, Diogo D, Lunet N: Hypertension prevalence, awareness, treatment, and control in mozambique: urban/rural gap during epidemiological transition. Hypertension 2009, 54(1):77-83.

42. Okwuonu CG, Ngoka SC, Chimezie OJ, Eze TH, Uwanurochi K, Mbanaso AU. Towards prevention of hypertension in Nigeria: A study of prehypertension and its associations among apparently healthy adults in Umuahia, South-East Nigeria. Int J Prev Med. 2015;2015(JULY).

43. Olayinka A, Owolabi MO, David A, Amole IO. Internet Journal of Medical Update Nigeria. 2015;10(2):10-9. 
American Journal of Health, Medicine and Nursing Practice

ISSN 2520-4017 (Online)

Vol.7, Issue 2, pp $1-14,2022$

www.ajpojournals.org

44. World Health Organization. A global brief on hypertension; silent killer, global public health crisis: World Health Day 2013. Geneva: Hypertens. 2013;9.

45. Cappuccino FP, Micah FB, Emmett L, Kerry SM, Antwi S, Martin-peprah R, et al. Hypertension in Ashanti, West Africa. 2004;1017-23.

46. Karmacharya BM, Koju RP, Logerfo JP, Chuen K, Chan G, Mokdad AH, et al. Awareness, treatment and control of hypertension in Nepal: findings from the Dhulikhel Heart Study. $2017 ; 1-8$.

47. Zhang Y, Moran AE. Trends in the Prevalence, Awareness, Treatment, and Control of Hypertension Among Young Adults in the United States, 1999 to 2014. Hypertension. 2017 Oct;70(4):736-742. DOI: 10.1161/HYPERTENSIONAHA.117.09801. Epub 2017 Aug 28. PMID: 28847890; PMCID: PMC5657525. 